Tohoku J. exp. Med., 1981, 135, 179-186

\title{
The Effects of Intermittent (Trapezoidal) Noise on Man
}

\author{
Kōtarō Yamamura, Naoki Maehara, Izumi Harabuchi, \\ Terukazu Sadamoto, Kiyohisa Takahashi* and Chieko \\ HAYAFUJI* \\ Department of Public Health, Sapporo Medical College, \\ Sapporo 060 and *Department of Medical Chemistry, \\ Tokyo Metropolitan Institute for Neurosciences, Tokyo 183
}

\begin{abstract}
Yamamura, K., Makhara, N., Harabuchi, I., Sadamoto, T., Takahashi, K. and HAyAFUJ, C. The Effects of Intermittent (Trapezoidal) Noise on Man. Tohoku J. exp. Med., 1981, 135 (2) 179-186 — Eight healthy students were exposed to intermittent noise to evaluate the effects of traffic noise on man. The experimental noise exposure conditions were as follows: Exp. 1: Control. Exp. 2: Peak level, $80 \mathrm{~dB}(\mathrm{~A})$; rise-decay time, 1 sec; duration, 3 sec; and duty cycle 8 sec (on fraction 25\%). Exp. 3: Peak level, $75 \mathrm{~dB}$ (A); rise-decay time, 500 msec; duration, $4.5 \mathrm{sec}$; and duty cycle, 8 sec (on fraction $50 \%$ ). In all experiments, the exposure time was $14 \mathrm{hr}$. Temporary threshold shift (TTS) growth was followed for $14 \mathrm{hr}$ while saliva cortisol levels were measured for a 24 -hr period. Although the coefficient of the regression line of TTS growth recorded in Exp. 1 or Exp. 3 was not statistically significant, the value in Exp. 2 was statistically significant. The circadian rhythm pattern of the saliva cortisol level (during a 24-hr period, mean of 8 examinees) was observed in the three experiments. Essentially, the early morning level of saliva cortisol was high, while the daytime level was relatively low. intermittent noise; TTS; saliva cortisol
\end{abstract}

In situations in which the amount of traffic has been as heavy as several ten thousand cars/day, the character of changing noise has usually been considered as steady state. There have already been many investigations concerning the effect of steady state noise on man (Environment Agency, Japan 1977; Yamamura and Takahashi 1978a; Kabuto and Suzuki 1979; Itoh et al. 1980; Itoh and Yamamura 1980; Yamamoto 1980). When traffic has not been very heavy, the characteristics of traffic noise have been considered as intermittent. There have not, however, been very many reports related to investigation of the biological responses induced by long time exposure to intermittent noise of a low sound level. A series of experiments to consider the influence of these factors was carried out by the authors (Yamamura and Aoshima 1980).

It is the purpose of the present study to investigate temporary threshold shift (TTS) and changes in circadian rhythm on saliva cortisol induced by long time exposure to intermittent noise of a lower sound level.

Received for publication, January 12, 1981. 


\section{Methods}

In each experiment, eight healthy male college students were examined once a week.

An $8 \mathrm{~m} \times 10 \mathrm{~m} \times 3 \mathrm{~m}$ room was employed and noise was absorved by a $50 \mathrm{~mm}$ thick covering of styrofoam on the ceiling and walls (excluding a window) and by a carpeted floor.

Each examinee sat approximately $50 \mathrm{~cm}$ away from an ALTEC Model 604-8G speaker (diameter, $50 \mathrm{~cm}$; set on a concrete block in the center of the room) and was instructed to direct one ear toward the speaker. The noise exposure (80 $\mathrm{dB}$ (A) and $75 \mathrm{~dB}(\mathrm{~A}))$ to the target ear of each examinee was maintained at the same level for all examinees.

Two persons were exposed to noise in one day. In this experiment, TTS growth and saliva cortisol levels were measured.

\section{Noise exposure conditions}

The method of noise production. Employing a noise generator (Rion Co. Random noise generator RN-01), the subjects were exposed to pink noise adjusted by electronic switch (Rion Co. SB-10 and TG-04). Each examinee was exposed to the pink noise by means of an amplifier (Yamaha Co. CA-200) and the speaker.

The time pattern of the changing noise level, and the relative octave band level of the trapezoidal noise are shown in Fig. 1. The background noise level was below $50 \mathrm{~dB}$ (A).

Noise patterns employed

Exp. 1: Control (non-noise exposure). The same exposure room was used and the

A
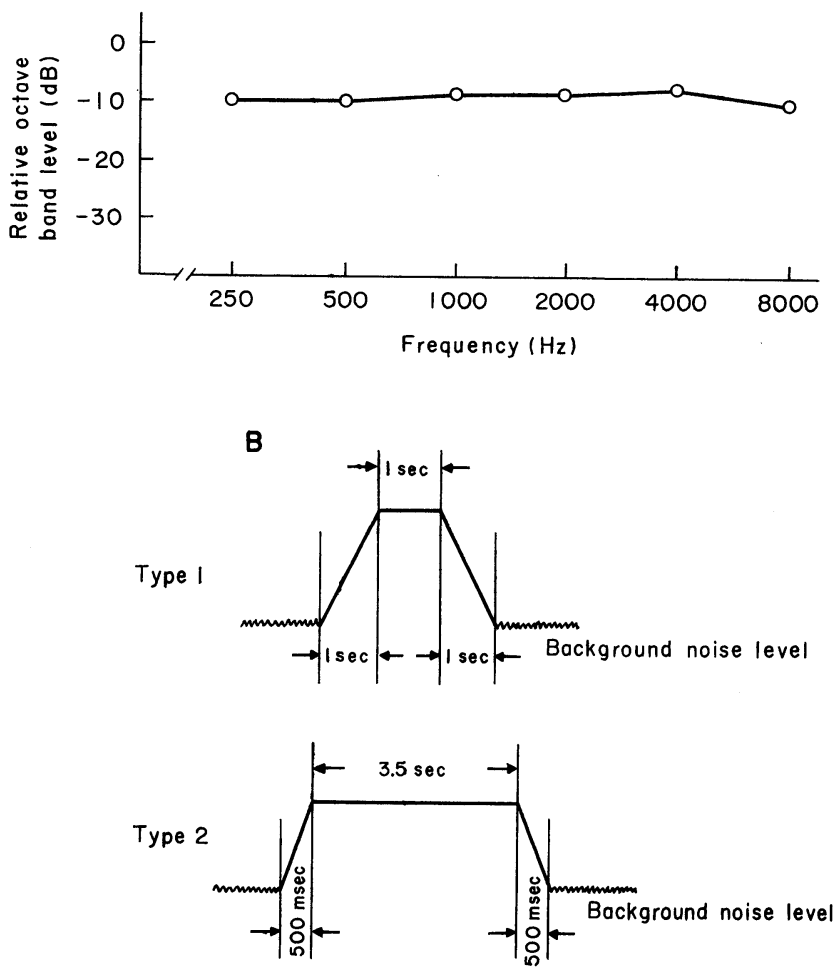

Fig. 1. Spectral analysis and the time pattern of trapezoidal noise.

A: Spectral analysis of trapezoidal noise. B: Time pattern of trapezoidal noise. 
back-ground noise level was below $50 \mathrm{~dB}(\mathrm{~A})$.

Exp. 2: Trapezoidal noise of the time pattern of Type 1 (Fig. 1B). Rise-decay time, 1 sec; duration, $3 \mathrm{sec;}$ peak level, $80 \mathrm{~dB}(\mathrm{~A})$; duty cycle, $8 \mathrm{sec}$ (the on fraction was about $25 \%$ ).

Exp. 3: Trapezoidal noise of Type 2 (Fig. 1B). Rise-decay time, $0.5 \mathrm{sec}$; duration, 4.5 sec; peak level, $75 \mathrm{~dB}(\mathrm{~A})$; duty cycle, 8 sec (the on fraction was about $50 \%$ ).

Onset of noise exposure was at 10:00 a.m. and exposure continued until 12:00 midnight, for a total of $14 \mathrm{hr}$ under each condition. After termination of noise exposure at 12:00 midnight, the subjects were allowed to sleep.

\section{Audiometry}

Measurement of hearing acuity was carried out with a Bēkēsy-type audiometer (Rion Co.) using a small audiometric booth (Rion Co., AT-4C).

The values of TTS after 2 min of cessation of noise exposure $\left(\mathrm{TTS}_{2}\right.$ ) at $4 \mathrm{kHz}$ (test frequency) were measured at the following noise exposure times in each experiment; before exposure, 10:10 a.m., 10:30 a.m., 11:00 a.m., 12:00 noon, 1:00 p.m., 2:00 p.m., 3:00 p.m., 4:00 p.m., 5:00 p.m., 6:00 p.m., 7:00 p.m., 8:00 p.m., 9:00 p.m., 10:00 p.m., 11:00 p.m. and 12:00 midnight.

At the time of the test for hearing acuity, an intermittent tone $(4 \mathrm{c} / \mathrm{sec})$ of $4 \mathrm{kHz}$ as a test tone was employed and a continuous test tone of $4 \mathrm{kHz}$ was not used.

\section{Determination of saliva cortisol}

Saliva samples were collected on the following schedule for a 24-hr period: before the onset of noise exposure (immediately before 10:00 a.m.), 1:00 p.m., 4:00 p.m., 7:00 p.m., 10:00 p.m., 1:00 a.m. (1 hr after termination of noise exposure), 4:00 a.m., 7:00 a.m. and 10:00 a.m.

Subjects sat in the above-mentioned position during the $14 \mathrm{hr}$ of noise exposure. Meals were served at about the following times; lunch around 1 p.m. and dinner around 7 p.m. Subjects were allowed to take other food and drink whenever they desired.

After gargling with water, two to three $\mathrm{ml}$ of saliva spontaneously secreted were collected from each examinee into a glass tube by means of a funnel for several minutes according to the above-mentioned schedule.

Samples were kept frozen at $-20^{\circ} \mathrm{C}$ for several hours in order to facilitate the separation of supernatant liquid and precipitate, and were then dissolved at room temperature. Dissolved samples were centrifuged at $3000 \mathrm{rpm}$ for $10 \mathrm{~min}$, with the supernatant liquid then being stored in a freezer at $-20^{\circ} \mathrm{C}$ until analyzed.

Saliva cortisol was determined by a competitive protein-binding radioassay according to the method of Murphy (Murphy 1967). The outline of the procedures is as follows: Three hundred $\mu \mathrm{l}$ of the saliva sample was added to $1 \mathrm{ml}$ of ethanol in a centrifuge tube. The solution was mixed and centrifuged. Five hundred $\mu \mathrm{l}$ of supernatant fraction were transferred to a small test tube. This supernatant fraction was air-dried. One $\mathrm{ml}$ of CBGisotope solution (including $5 \mu \mathrm{l}$ human plasma, $0.035 \mu \mathrm{C}{ }^{3} \mathrm{H}$-cortisol, $995 \mu \mathrm{l}$ distilled water) was added to the tube. This mixture was shaken well and heated at $37^{\circ} \mathrm{C}$ in a water bath for $10 \mathrm{~min}$. Immediately after heating, it was cooled in an ice water bath for $15 \mathrm{~min}$. About $145 \mathrm{mg}$ of Florisil was added to this mixture, and the mixture was then stirred vigorously for $2 \mathrm{~min}$ in an ice water bath. The upper layer of this mixture $(500 \mu \mathrm{l})$ was added to Bray's solution. The sample was subjected to radioassay in a liquid scintillation counter (Packard 3320).

\section{RESULTS}

\section{TTS growth}

The results of $\mathrm{TTS}_{2}$ measurement induced at a test frequency of $4 \mathrm{kHz}$ are shown in Figs. 2 and 3 as the average of eight subjects. In Fig. 2, the mean values and S.E. of the $\mathrm{TTS}_{2}$ (solid circles) of Exp. 2 are shown. The regression line 


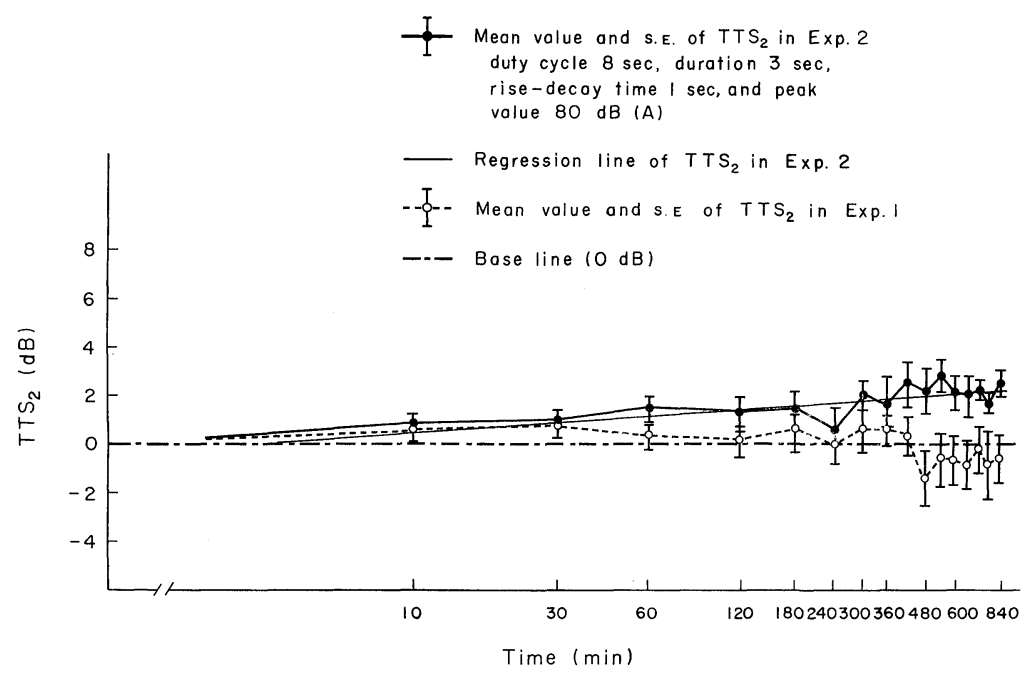

Fig. 2. TTS growth induced by intermittent noise exposure (Exp. 1 and Exp. 2). Test frequency: $4 \mathrm{kHz}$.

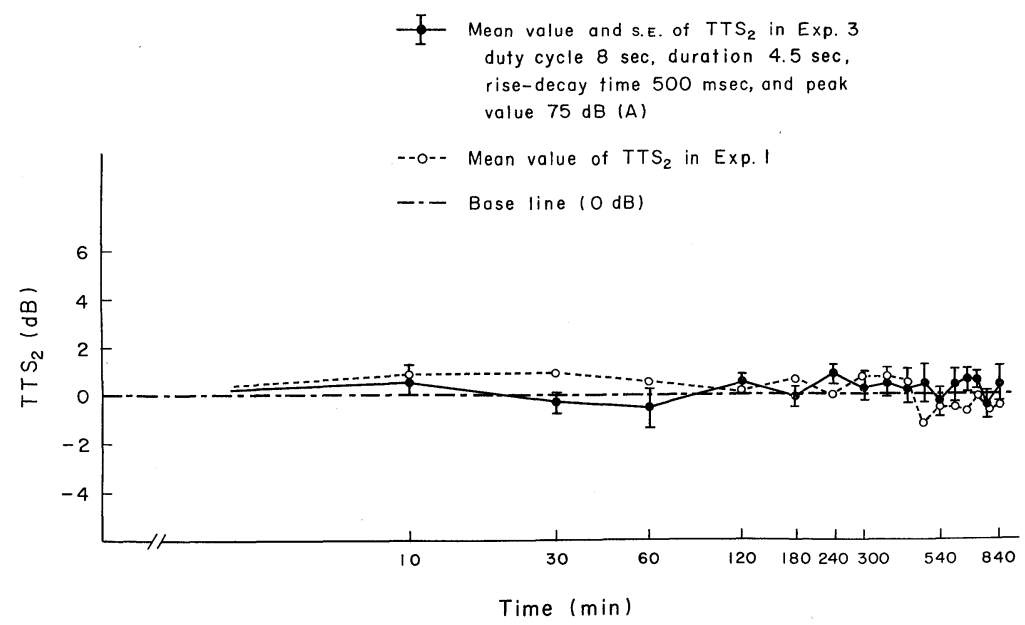

Fig. 3. TTS growth induced by intermittent noise exposure (Exp. 1 and Exp. 3). Test frequency: $4 \mathrm{kHz}$.

for Exp. 2 is also shown. The mean values and s.E. of $\mathrm{TTS}_{2}$ in Exp. 1 (open circles, connected by a broken-line) are also shown in Fig. 2.

The regression coefficient of TTS growth in Exp. 2 was statistically significant $\left(F=7.90>F^{1}{ }_{126}(0.01)=6.84\right)$, but that of Exp. 1 was not significant, $(F=3.46$ $\left.<F^{126}(0.05)=3.92\right)$. The standard error of Exp. 1 was larger than those of Exp. 2 and Exp. 3.

In Fig. 3, the mean values of $\mathrm{TTS}_{2}$ (solid circles) for each exposure time during the 840 min in Exp. 3 are shown. The regression coefficient of TTS growth in Exp. 3 was not significant $\left(F=0.604 \ll F^{1}{ }_{126}(0.05)=3.92\right)$ statistically. 


\section{Measurement of saliva cortisol}

The results of the determination of saliva cortisol are shown in Fig. 4.

Changes in saliva cortisol levels (means of the 8 subjects) with or without noise exposure during the 24-hr period tended to occur and reach a maximum early in the morning, followed by a more gradual decline, reaching a minimum in the later part of the day up to midnight (Fig. 4).

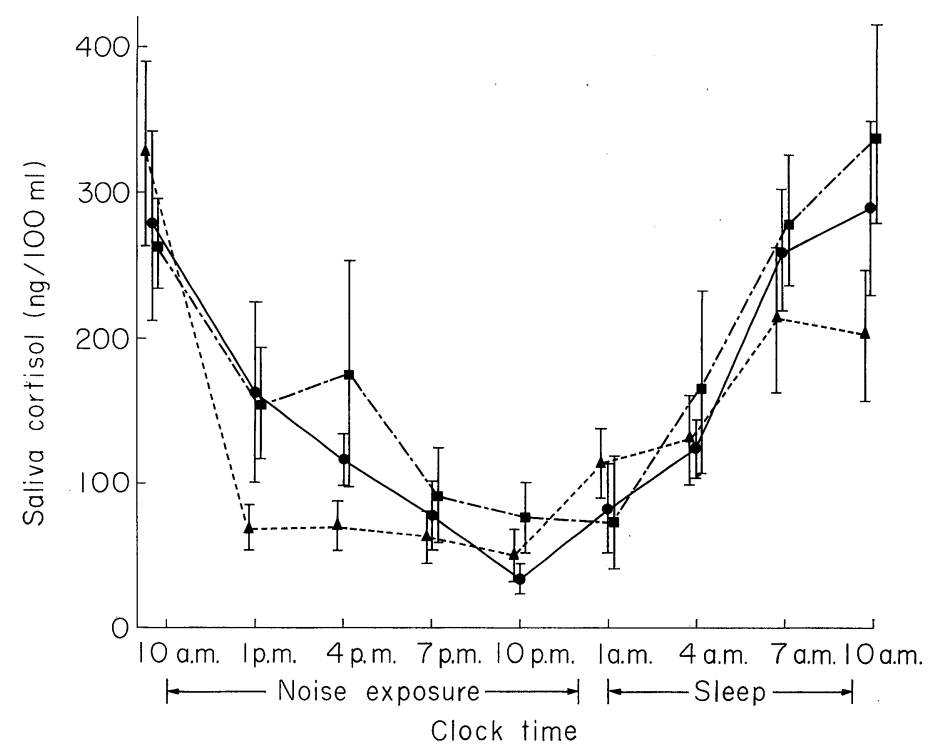

Fig. 4. Circadian rhythm of saliva cortisol levels induced by trapezoidal noise exposure. Mean士s.E.

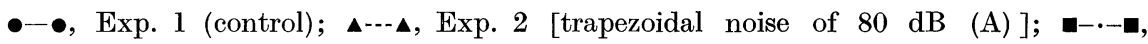
Exp. 3 [trapezoidal noise of $75 \mathrm{~dB}(\mathrm{~A})$ ].

In addition, the saliva cortisol level, at 3 to $6 \mathrm{hr}$ after the onset of exposure to trapezoidal noise of $80 \mathrm{~dB}(\mathrm{~A})(\operatorname{Exp} .2)$, appeared to have a tendency to be slightly lower than that of the control (Exp. 1). In Exp. 3 (trapezoidal noise of $75 \mathrm{~dB}(\mathrm{~A})$ ), the saliva cortisol level at 4 p.m. was slightly higher than that of control. These differences in the cortisol level between the exposed and the control at each clock time, however, were statistically insignificant $(p>0.05$ by $t$-test).

\section{Discussion}

It has been considered that the pathogenesis of noise induced TTS (NITTS) is due to loss of rigidity of the outer hair cell cilia in the cochlear (Lim 1980). There seems, therefore, to be little doubt that repeated TTS growth may be a cuase of damage to the hair cells and that it may produce a permanent threshold shift (PTS). In our previous investigations, $8 \mathrm{hr}$ trapezoidal noise exposure of $80 \mathrm{~dB}(\mathrm{~A})$ (peak level) with an on fraction of $25 \%$ (Yamamura and Aoshima 1980), or $555 \mathrm{~min}$ of 
trapezoidal noise exposure of $80 \mathrm{~dB}(\mathrm{~A})$ with an on fraction of $20 \%$ (Yamamura et al. unpublished) did not induce significant TTS growth at $4 \mathrm{kHz}$. Environmental noise pollution, such as that due to automobiles, however, is present during both night and day. Mills et al. (1979) have suggested that when the exposure level is constant, TTS growth increases during $13-16 \mathrm{hr}$, after which it reaches a plateau (asymptotic threshold shift, ATS). It now seems that the exposure time in our previous experiments (555 min or $480 \mathrm{~min}$ of intermittent noise exposure) was too short for evaluation of the trapezoidal noise.

For these reasons, a 14-hr exposure to trapezoidal noise was employed in the present study. In the control experiment of Exp. 1, the standard deviations of TTS were larger than those of Exp. 2 and Exp. 3, and even slightly negative values of TTS were observed. Since the test of hearing acuity was considered as a psychophysiological function test, a few elevations of the hearing threshold due to the effects of training were considered in relaxation time without noise exposure. Under this 14-hr noise exposure with a peak level of $80 \mathrm{~dB}(\mathrm{~A})$, significant TTS growth was observed. The TTS growth induced by $14 \mathrm{hr}$ trapezoidal noise with a peak level of $75 \mathrm{~dB}(\mathrm{~A})$ and an on fraction of $50 \%$, however, was not significant. In Exp. 3, although the on fraction was twice those in Exp. 2, the noise peak level was $5 \mathrm{~dB}$ below those of Exp. 2. The equivalent sound level (Leq) of the above trapezoidal noise was the same with steady state noise of $74 \mathrm{~dB}(\mathrm{~A})$ in Exp. 2 and $72 \mathrm{~dB}(\mathrm{~A})$ in Exp. 3. In the authors' previous article, it was reported that, with $8 \mathrm{hr}$ steady state noise exposure (the level slightly higher than $70 \mathrm{~dB}(\mathrm{~A})$ ), TTS increased significantly (Itoh and Yamamura 1980), but that TTS growth induced by intermittent noise exposure (peak level $75 \mathrm{~dB}(\mathrm{~A})$ ) was lower than that of the same Leq of steady state noise (Yamamura unpublished). In addition, while $8 \mathrm{hr}$ noise exposure of $70 \mathrm{~dB}(\mathrm{~A})$ did not induce significant TTS growth, noise exposure of $75 \mathrm{~dB}(\mathrm{~A})$ did (more than $5 \mathrm{~dB}$ ) (Yamamura and Takahashi 1978a).

The effects on hearing following intermittent noise exposure may have been less than that of the same Leq of steady state noise, because the off time of one duty cycle might induce recovery of hearing acuity (Shoji et al. 1969). This would explain why when the Leq of Exp. 3 was slightly over $70 \mathrm{~dB}(\mathrm{~A})$, the noise exposure of Exp. 3 did not induce significant TTS growth. In Exp. 2, the peak value of intermittent noise was $5 \mathrm{~dB}(\mathrm{~A})$ higher than that of Exp. 3 and the Leq was $2 \mathrm{~dB}(\mathrm{~A})$ higher. For this reason, slight TTS growth may have been obtained in Exp. 2. This trapezoidal noise of $80 \mathrm{~dB}(\mathrm{~A})$ is equal in level to the noise from a diesel truck on the load side (Igawa 1974).

Many discussions have already been presented on the effect on man of the adrenocortical response to noise (Osada et al. 1972; Osada 1980; Satō et al. 1980). There have been no reports concerning investigation of the 24-hr responses induced by long time noise exposure, including the effect after the termination of noise exposure, from the standpoint of circadian rhythm.

There is a highly significant correlation between the saliva cortisol level and the blood cortisol level (Shannon et al. 1966; Tanaka et al. 1979) and stress is not observed 
at the time of saliva collection (Yamamura and Takahashi 1978b). Therefore, the authors examined the effect of circadian rhythm on the saliva cortisol level due to intermittent noise exposure.

In Exp. 2, no significant difference was observed between mean saliva cortisol level at $3 \mathrm{hr}$ or $6 \mathrm{hr}$ after the onset of noise exposure and that of the control experiment. Either in Exp. 3, no significant difference was observed between the mean saliva cortisol level at $6 \mathrm{hr}$ after the onset of noise exposure and that of the Exp. 1.

The results obtained in the present experiments support, to a certain degree, the results on urinary 17-OHCS levels in a series of our experiments. Namely, no significant changes were observed in urinary 17-OHCS levels due to intermittent noise exposure of $80 \mathrm{~dB}(\mathrm{~A})$ (on fraction: $25 \%$ ) or steady state noise of $70 \mathrm{~dB}(\mathrm{~A})$ $80 \mathrm{~dB}(\mathrm{~A})$ for $8 \mathrm{hr}$, although saliva cortisol levels differed slightly from the levels of the urinary 17-OHCS obtained from stored urine.

Tatai et al. (1967) reported that urinary excretion of 17-OHCS increased in accordance with noise level up to a certain point, $80 \mathrm{~dB}(\mathrm{~A})$ or $85 \mathrm{~dB}(\mathrm{~A})$, and that it decreased afterwards under short-time exposure. Furthermore, in our previous experiment on intermittent noise of $80 \mathrm{~dB}(\mathrm{~A})$ for $8 \mathrm{hr}$, urinary excretion of 17-OHCS increased significantly along with decreases in the percentage of onfraction; i.e. $5 \%$ or $10 \%$ (Yamamura and Aoshima 1980). As to the effect of noise on plasma cortisol, which is representative of adrenocortical function, the following results were obtained. At a short-time noise exposure of about $100 \mathrm{~dB}(\mathrm{C})$, the plasma cortisol level increased significantly in one experiment (Follenius et al. 1980). In another case (Satō et al. 1980) a significant difference was not observed in noise exposure of $90 \mathrm{~min}$. In our present experiments, however, it was observed that long time exposure to intermittent noise of a short duty-cycle did not induce statistically significant changes in the saliva cortisol level as compared with the control experiment. Osada (1980) also reported that changes in urinary 17-OHCS levels decreased after several hours of noise exposure. The results of our experiments suggest that the mechanism of adaptation in the human body to noise exposure might involve adaptations of the diencephalohypophysial and adrenal gland systems following noise exposure.

\section{References}

1) Environment Agency, Japan (1977) Survey for Health of Residents Living along the Highway, Tokyo, pp. 1-93. (Japanese)

2) Follenius, M., Brandenberger, G., Lecornu, C., Simeoni, M. \& Reinhardt, B. (1980) Plasma catecholamines and pituitary adrenal hormones in response to noise exposure. Europ. J. appl. Physiol., 43, 253-261.

3) Igawa, K. (1974) Traffic noise. In: Handbook of Noise Control, edited by S. Morita, Gihōdō, Tokyo, pp. 115-126. (Japanese)

4) Itoh, A., Rikimaru, Y., Shinshi, Y., Hiramatsu, K., Takagi, K. \& Yamamoto, T. (1980) Hearing loss induced by traffic noise. Jpn. J. Hyg., 35, 277. (Japanese, Abstract)

5) Itoh, F. \& Yamamura, K. (1980) An investigation of traffic noise on man. Biotelemetry, 5 (Proceedings of 5 International Biotelemetry), 219-222. (Abstract) 
6) Kabuto, M. \& Suzuki, S. (1979) Temporary threshold shift from transportation noise. $J$. acoust. Soc. Amer., 66, 170-175.

7) Lim, D.J. (1980) Cochlear anatomy related to cochlear microphonics. A review. $J$. acoust. Soc. Amer., 67, 1686-1695.

.8) Mills, J.H., Gilbert, R.H. \& Adkins, W.Y. (1979) Temporary threshold shift in humans exposed to octave band of noise for 16 to 24 hours. J. acoust. Soc. Amer., 65, 1238-1248..

9) Murphy, B.E.P. (1967) Some studies of the protein-binding of steroids and their application to the routine micro and ultramicro measurement of various steroids in body fluids by competitive protein-binding radioassay. J. clin. Endocr. Metab., 27, 973-990.

10) Osada, Y. (1980) Effects of noise on man. In: Handbook of Sanitary Engineering (Noise and Vibration), edited by H. Shoji, T. Yamamoto and N. Hatakeyama, Asakura Shoten, Tokyo, pp. 81-110. (Japanese)

11) Osada, Y., Yoshida, K., Ogawa, S., Hirokawa, A., Ohokubo, C., Haruta, K. \& Miyazaki, K. (1972) Physiological effects of aircraft noise, especially of level and number of exposures. Bull. Inst. publ. Health, 21, 51-59. (Japanese)

12) Satō, H., Matsui, K. \& Sakamoto, H. (1980) Comparative studies on adrenocortical response to noise in men and rats. Jpn. J. Hyg., 35, 499-507. (Japanese)

13) Shannon, I.L., Stevens, C.B. \& Katz, F.H. (1966) Parotid fluid steroid responses to ACTH in surgically confirmed cases of Cushing's syndrome. J. clin. Endocr. Metab., 26, 11-13.

14) Shoji, H., Yamamoto, T., Takagi, K. \& Tokuda, S. (1969) Studies on TTS produced by intermittent exposure of noise. Jpn. J. Ind. Health, 11, 345-350.

15) Tanaka, M., Honda, Y., Tanba, S., Hanada, K., Takahashi, K., Takahashi, Y. \& Nakakura, Y. (1979) Circadian rhythm of saliva cortisol level (Part 1). Folia endocr. jap., 54, 326.

16). Tatai, K., Osada, Y., Tsunashima, S., Yoshida, K. \& Ogawa, S. (1967) Experimental Studies on the influence of noise on physiological functions of human body. II. Bull. Inst. publ. Health, 16, 105-111. (Japanese)

17) Yamamoto, T. (1980) TTS growth induced by steady stste noise of 24 hours. In: The Report of Environment Agency, Japan. (Japanese)

18) Yamamura, K. \& Takahashi, K. (1978a) Fluctuation of temporary threshold shift (TTS) and urinary 17-OHCS excretion induced by steady state noise. Igaku no Ayumi, 104, 744-746. (Japanese)

19) Yamamura, K. \& Takahashi, K. (1978b) The effect of intermittent noise on man. Jpn. J. Hyg., 33, 521-527. (Japanese)

20) Yamamura, K. \& Aoshima, K. (1980) An investigation of biological response induced by intermittent noise (trapezoidal noise). Europ. J. appl. Physiol., 44, 9-16. 